\title{
Norms for cerebellum in Sudanese -A morphometric MRI based study
}

\author{
Hiba Osman Mohmmed Sied Ahmed ${ }^{1},{ }^{*}$ Hussein Ahmed Hassan ${ }^{1}$ and \\ Caroline Edward Ayad ${ }^{1}$ \\ ${ }^{1}$ Sudan University of Science and Technology-Khartoum-Sudan \\ Corresponding author: ${ }^{*}$ Caroline Edward Ayad
}

\begin{abstract}
The cerebellum is one of the most important structures in the posterior cranial fossa. The objectives of this study were to characterize the cerebellum and cerebrum by measuring the cerebellum height, vermians $A P$ width in the mid-sagittal plane, the maximum cerebellar hemispheric width in axial plane and the cerebrum length and width, using MRI as well as to determine the impact of age and gender on the measurements in healthy Sudanese adults. The data were obtained from MR multi planes images done for 100 healthy Sudanese subjects, their mean age was $42.36 \pm 17.87$ years old (Min $=14.00$, Max=80.00 years).

Norms for Sudanese cerebellum and cerebrum measurements were established. The cereberum length was affected by age significantly at $p=0.004$; however no age related differences were noticed in the cerebellum measurements. The degree of the reduction in the cerebellar measurements is mild and unlikely to be significant. Smaller measurements of cerebellum and cerebrum were noticed in females than males, where the cerebellum hemisphere maximum width and cerebrum length were affected significantly by gender, while the cerebellum height and AP vermian width were not significantly correlated with gender. The results of this study provide a valuable addition to the normative database of the cerebellar and cerebrum anatomy for Sudanese .These data are an attempt to support the norms of the cerebellum data measured in axial and saggital images. It should be taken into account in functional imaging studies of aging, when the cerebellum is considered as an appropriate structure for reference and normalization for Sudanese.
\end{abstract}

Keywords - Cerebellum, Brain, MRI, aging, neuroanatomy .

\section{INTRODUCTION}

The cerebellum is one of the most important structures in the posterior cranial fossa, it provided higher cognitive functions. Additionally, the cerebellum has a mission in behavioral and psychiatrically diseases. [1-3] Cerebellum also have a role on working memory function. $[4,5]$

Cerebellum continues to improve during childhood and adolescence, suggesting that it may be undergoing significant development during this period. Few is known regarding normal development of the cerebellum during life as mentioned by Diamond et al, 2000[6].Another study raised questions about whether the developmental curves are different between females and males. [7]Studies have mentioned that, the cerebellum develops from childishness to puberty and accesses the peak levels between 10 and 13 years old for both genders.[8] It develops over a long period: it is one of the first structures in the brain to begin to differentiate, but one of the last to mature as mentioned by Susan et al. 2008. [9]

Aging of the human brain is a differential process in which significant declining in some regions coexists with relative safeguarding in others. [10-12]Although this issue is noticeable in the cerebral cortex, it is unclear whether it can be extended to the structures of the posterior fossa.

Differential aging of the cerebellar vermis lobules has also been reported. [13, 14] In one study, however, an opposite pattern was observed, that is, a significant negative age trend was found for the anterior vermis. $[15,16]$

Several investigators have observed gender related differences in gross cerebellar neuroanatomy. Males were shown to have larger cerebella than those of age-matched females, although in these reports the possibility that these differences could have reflected sexual dimorphism of body size was not consistently ruled out.[14]Little is known regarding differences in the development of cerebellar compartments, despite their having important characteristics regarding function, anatomical connections with the cortex, and an important role in neurodevelopment disorders as mentioned by Ramnani et al, 2006.[17]

An awareness of normal neuroanatomic variability is important for understanding pathologic changes. In regard to the posterior fossa structures, most of the researches record of in vivo studies are few and there is a need for normative data about the cerebellum .To the best of our knowledge, no Sudanese studies were obtained and included measurements of the same individuals in the axial, and sagittals of MR images as well, in this current prospective study, we examined age and gender related differences in the height, AP vermian width in 
saggital plane and the maximum transverse hemisphere width of the cerebellum in the axial plane ,as well the length and width of the cerebrum were measured in the axial plane for Sudanese Healthy individuals.

\section{MATERIALS AND METHODS}

This is descriptive analytical study .It was performed in Khartoum state, Yastabshiroon Hospital Radiology Department, MRI section. The study was obtained during the period extended from 2014-2017. The study was performed on 100 patients .39 were males and 61were females with different ages at range (1480)years, mean age was $42.36 \pm 17.87$ years old(Min $=14.00$, Max $=80.00$ years). The ages between $14-24$ years constituting 19 cases, ages between 25-34 were 14 subjects, and ages between 35-44 years were 23, while 45-54 years old were 20,55-64 were 10 and ages $>65$ were 14 subjects .All patients have undergone MRI brain exam complaining of headache, and their final diagnoses is normal. Any patient has problem to perform MRI brain such as patients with metallic foreign body in brain or brain clips or abnormalities at any part of cerebellum or cerebrum were excluded.

\subsection{MRI machine.}

This machine is open machine and manufactured in America in 2005 and assembly in China, GE exit 0.2 Tesla .The RF Range in examination from(512-192)HZ .The slice thickness used in MRI brain was 5mm routinely except in the examination for small region such as pituitary gland or optic foremen. The matrix (options) were $256 \times 256$ or $512 \times 512$.Field of view (options) were small, medium and large.

\subsection{The technique used and protocols:}

Three planes were taken: axial $\left(\mathrm{T}_{1}, \mathrm{~T}_{2}, \mathrm{~T}_{1}\right.$ with flair), sagittal $\mathrm{T}_{1}$ and coronal $\mathrm{T}_{2}$ section as routine .The measurements were done in: axial $\mathrm{T}_{2}$ FSE. Firstly: patients were prepared to enter the MRI room by taking any metallic substance outside his /her body. In the cases where anesthesia is needed, it was applied. The sequence of the exam was explained clearly for all of the patients. Secondly: the head coil was applied, then the foam pads and ear plugs to ensure the immobilization and comfortable of patients. Two control lines were applied; one is axial and the another is sagittal, the first coronal and sagittal crosses the nasion area ,the second coronal pass just at the external orbital line level, then the scan start from vertex till the base of skull.

\subsection{Method of measurements:}

\subsubsection{Measurements done for the cerebellum at the axial plane:}

First measurement was taken in axial $\mathrm{T}_{2}$ FSE in region of interest for the cerebellum at the inner borders. The curser was at the wider point in inner border of left side of cerebellum it was pulled to another symmetrical right border, and this measurement called cerebellum width at axial image.

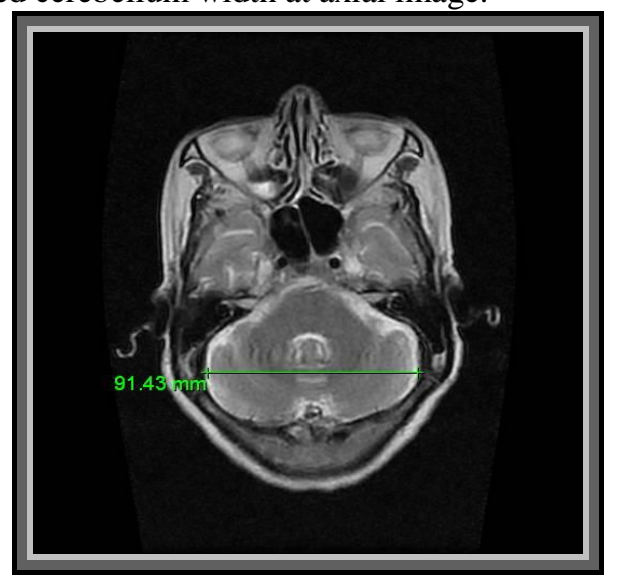

Figure (1) shows the maximum cerebellum hemisphere width in axial images

\subsubsection{Sagittal cerebellum:}

In this view the image was at mid saggital where the brain stem (mid brain,pons and medllua oblangata) was clear, and in this point the cerebellum height and the AP vermis width reach the maximum value ,then the curser at most upper point was positioned and was pulled till reach the lower point in another side and this measuring called cerebellum height at sagittal plane .Then the curser was moved till it reach the wider point at anterior portion and curser was pulled till it reached the posterior side and this reading called the AP cerebellum vermis width in mid sagittal plane image. 

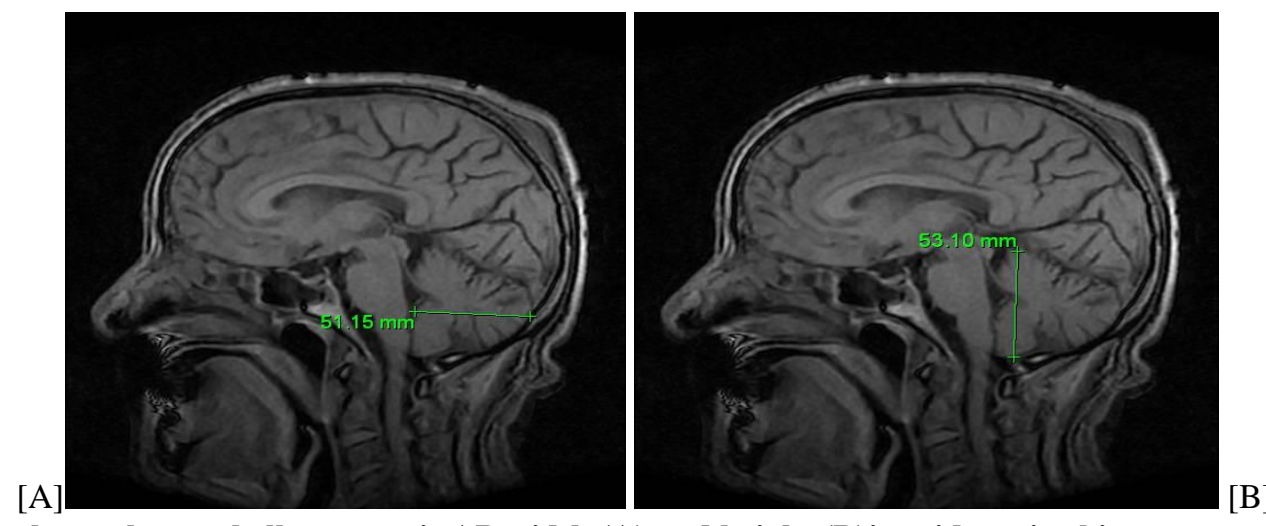

Figure (2) shows the cerebellum vermis AP width (A) and height (B)in mid sagittal images

2.3.3 Measurements done for length and width of the cerebrum at the axial plane:

The scanning was continued to upper cuts till the area of the lateral ventricles appear as shown as capital ( $\mathrm{H}$ )in this point the measurement of cerebrum was taken ,the curser was positioned at inner border of hemispheres of the brain in mid line at the level of mid lateral ventricle then a line was drawn till it reach the symmetrical point at lower bottom point in image and this measure called cerebrum length at axial image .the curser was drawn till the more width point of cerebrum in the same view and was drawn from the left point from inner border till it reached the right point in the other side, and this readings were called the cerebrum width at axial image.
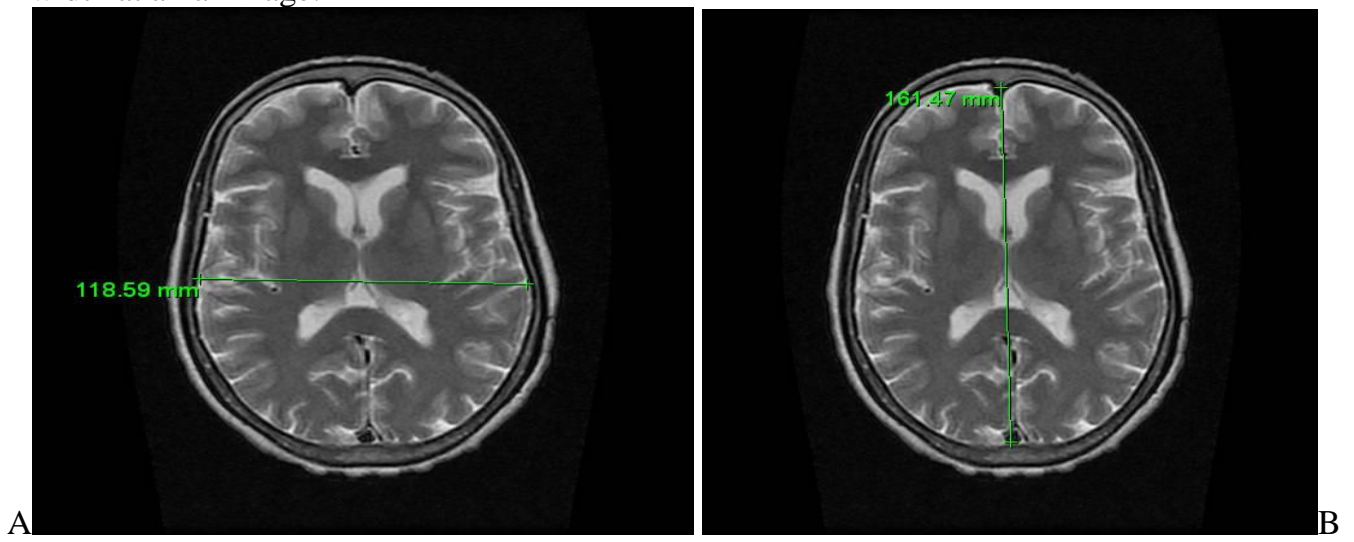

Figure (2) shows the cerebrum width (A) and Length (B)in axial images

\subsection{Ethical concerns:}

Verbal consent was firstly obtained from all potential participants. The aims, benefits of the present study were explained to all participants in details. Medical, history of all study subjects posing as (sample) were thoroughly reviewed directly from participants themselves and those with conditions that may in any way, alter the findings of the current study were excluded.

\section{TABLES AND FIGURES}

Table 1: Descriptive statistics of cerebellum and cerebrum measured in axial and saggital planes images

\begin{tabular}{|l|c|c|c|c|}
\hline \multicolumn{1}{|c|}{ Anatomical part/plane $\quad(\mathbf{n = 1 0 0})$} & $\begin{array}{c}\text { Min } \\
(\mathrm{mm})\end{array}$ & $\begin{array}{c}\text { Max } \\
(\mathrm{mm})\end{array}$ & $\begin{array}{c}\text { Mean } \\
(\mathrm{mm})\end{array}$ & Std. V \\
\hline Cerebellum hemispheric maximum width -Axial & 64.29 & 114.76 & 93.54 & 7.70 \\
\hline Cerebellum height-Saggital & 37.23 & 70.52 & 47.01 & 4.46 \\
\hline Cerebellum vermis AP width-Saggital & 27.78 & 441.98 & 41.83 & 41.17 \\
\hline Cerebrum length -Axial & 111.91 & 175.89 & 157.42 & 8.53 \\
\hline Cerebrum width -Axial & 108.44 & 146.20 & 120.75 & 5.44 \\
\hline
\end{tabular}

Table 2: Descriptive statistics of the measured cerebellum hemisphere maximum width, height, cerebellum vermis AP Width and cerebrum length and width classified according to age

\begin{tabular}{|c|c|c|c|c|c|c|c|}
\hline Anatomical part/plane & Age Class & $\mathrm{N}$ & $\begin{array}{l}\text { Mean } \\
(\mathrm{mm})\end{array}$ & Std. v & $\begin{array}{c}\text { Min } \\
(\mathrm{mm})\end{array}$ & $\begin{array}{c}\text { Max } \\
(\mathrm{mm})\end{array}$ & P-value \\
\hline \multirow{4}{*}{ Cerebellum hemisphere maximum width- Axial } & $14-24$ & 19 & 92.29 & 8.43 & 64.29 & 102.45 & \multirow{4}{*}{.729} \\
\hline & $25-34$ & 14 & 94.16 & 5.75 & 84.76 & 108.16 & \\
\hline & $35-44$ & 23 & 95.00 & 6.63 & 79.86 & 106.24 & \\
\hline & $45-54$ & 20 & 92.60 & 6.74 & 71.01 & 108.12 & \\
\hline
\end{tabular}


Norms for cerebellum in Sudanese -A morphometric MRI Based study

\begin{tabular}{|c|c|c|c|c|c|c|c|}
\hline & $55-64$ & 10 & 91.54 & 12.38 & 67.07 & 104.37 & \\
\hline & $65+$ & 14 & 94.98 & 7.73 & 87.14 & 114.76 & \\
\hline & Total & 100 & 93.54 & 7.70 & 64.29 & 114.76 & \\
\hline \multirow{7}{*}{ Cerebellum height -Sagital } & $14-24$ & 19 & 46.40 & 4.07 & 38.69 & 52.62 & \multirow{6}{*}{.387} \\
\hline & $25-34$ & 14 & 46.87 & 3.33 & 41.20 & 51.10 & \\
\hline & $35-44$ & 23 & 46.37 & 4.58 & 37.23 & 61.03 & \\
\hline & $45-54$ & 20 & 49.00 & 6.15 & 42.66 & 70.52 & \\
\hline & $55-64$ & 10 & 46.98 & 3.35 & 40.96 & 50.22 & \\
\hline & $65+$ & 14 & 46.19 & 3.30 & 39.67 & 50.75 & \\
\hline & Total & 100 & 47.01 & 4.46 & 37.23 & 70.52 & \\
\hline \multirow{7}{*}{ Cerebellum vermis AP width -Sagital } & $14-24$ & 19 & 37.92 & 4.51 & 30.26 & 45.66 & \multirow{6}{*}{.386} \\
\hline & $25-34$ & 14 & 39.31 & 7.13 & 32.25 & 53.80 & \\
\hline & $35-44$ & 23 & 36.97 & 4.30 & 27.78 & 44.87 & \\
\hline & $45-54$ & 20 & 60.60 & 90.91 & 29.78 & 441.98 & \\
\hline & $55-64$ & 10 & 36.44 & 3.38 & 30.26 & 40.10 & \\
\hline & $65+$ & 14 & 34.69 & 4.58 & 27.78 & 45.21 & \\
\hline & Total & 100 & 41.83 & 41.17 & 27.78 & 441.98 & \\
\hline \multirow{7}{*}{ Cerebrum length- Axial } & $14-24$ & 19 & 157.57 & 6.88 & 142.33 & 175.89 & \multirow{6}{*}{.004} \\
\hline & $25-34$ & 14 & 165.57 & 4.98 & 157.83 & 173.90 & \\
\hline & $35-44$ & 23 & 155.92 & 6.55 & 142.38 & 171.91 & \\
\hline & $45-54$ & 20 & 156.64 & 8.37 & 139.31 & 167.84 & \\
\hline & $55-64$ & 10 & 155.68 & 16.14 & 111.91 & 167.63 & \\
\hline & $65+$ & 14 & 153.83 & 3.95 & 146.71 & 162.39 & \\
\hline & Total & 100 & 157.41 & 8.53 & 111.91 & 175.89 & \\
\hline \multirow{7}{*}{ Cerebrum width -Axial } & $14-24$ & 19 & 119.58 & 5.79 & 109.49 & 129.55 & \multirow{6}{*}{.319} \\
\hline & $25-34$ & 14 & 121.51 & 5.27 & 111.19 & 127.25 & \\
\hline & $35-44$ & 23 & 120.80 & 4.42 & 113.79 & 129.59 & \\
\hline & $45-54$ & 20 & 120.41 & 4.60 & 108.44 & 129.44 & \\
\hline & $55-64$ & 10 & 124.17 & 8.74 & 113.81 & 146.20 & \\
\hline & $65+$ & 14 & 119.51 & 4.61 & 113.96 & 127.64 & \\
\hline & Total & 100 & 120.75 & 5.44 & 108.44 & 146.20 & \\
\hline
\end{tabular}

Table 3: Descriptive statistics of the measured cerebellum hemisphere maximum width, height, cerebellum vermis AP Width and cerebrum length and width classified according to gender

\begin{tabular}{|c|c|c|c|c|c|}
\hline Anatomical part/plane & Gender & $\mathrm{N}$ & $\begin{array}{l}\text { Mean } \\
(\mathrm{mm})\end{array}$ & Std. V & P-value \\
\hline \multirow{2}{*}{$\begin{array}{l}\text { Cerebellum hemisphere maximum width- } \\
\text { Axial }\end{array}$} & Male & 39 & 95.51 & 8.98 & \multirow[t]{2}{*}{.040} \\
\hline & Female & 61 & 92.28 & 6.53 & \\
\hline \multirow{2}{*}{ Cerebellum height-Sagital } & Male & 39 & 46.79 & 4.39 & \multirow[t]{2}{*}{.705} \\
\hline & Female & 61 & 47.14 & 4.53 & \\
\hline \multirow{2}{*}{ Cerebellum vermis AP width-Sagital } & Male & 39 & 46.88 & 65.16 & \multirow[t]{2}{*}{.330} \\
\hline & Female & 61 & 38.61 & 8.98 & \\
\hline \multirow{2}{*}{ Cerebrum length -Axial } & Male & 39 & 160.37 & 7.41 & \multirow[t]{2}{*}{.005} \\
\hline & Female & 61 & 155.52 & 8.71 & \\
\hline \multirow[t]{2}{*}{ Cerebrum width - Axial } & Male & 39 & 121.48 & 4.66 & \multirow[t]{2}{*}{.283} \\
\hline & Female & 61 & 120.28 & 5.88 & \\
\hline
\end{tabular}




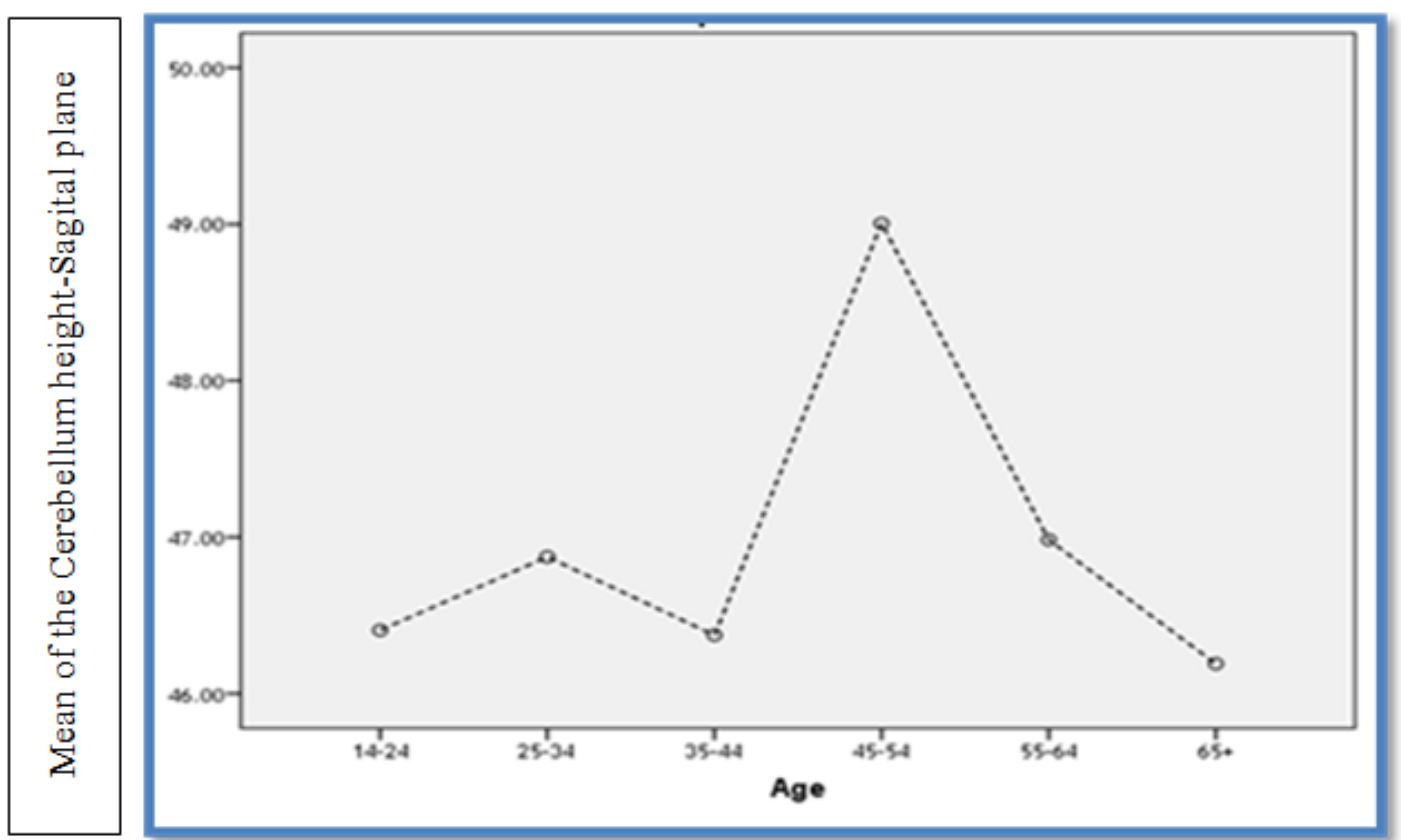

Figure 3: The mean plot of the measured cerebellum height at saggital plane in different age groups

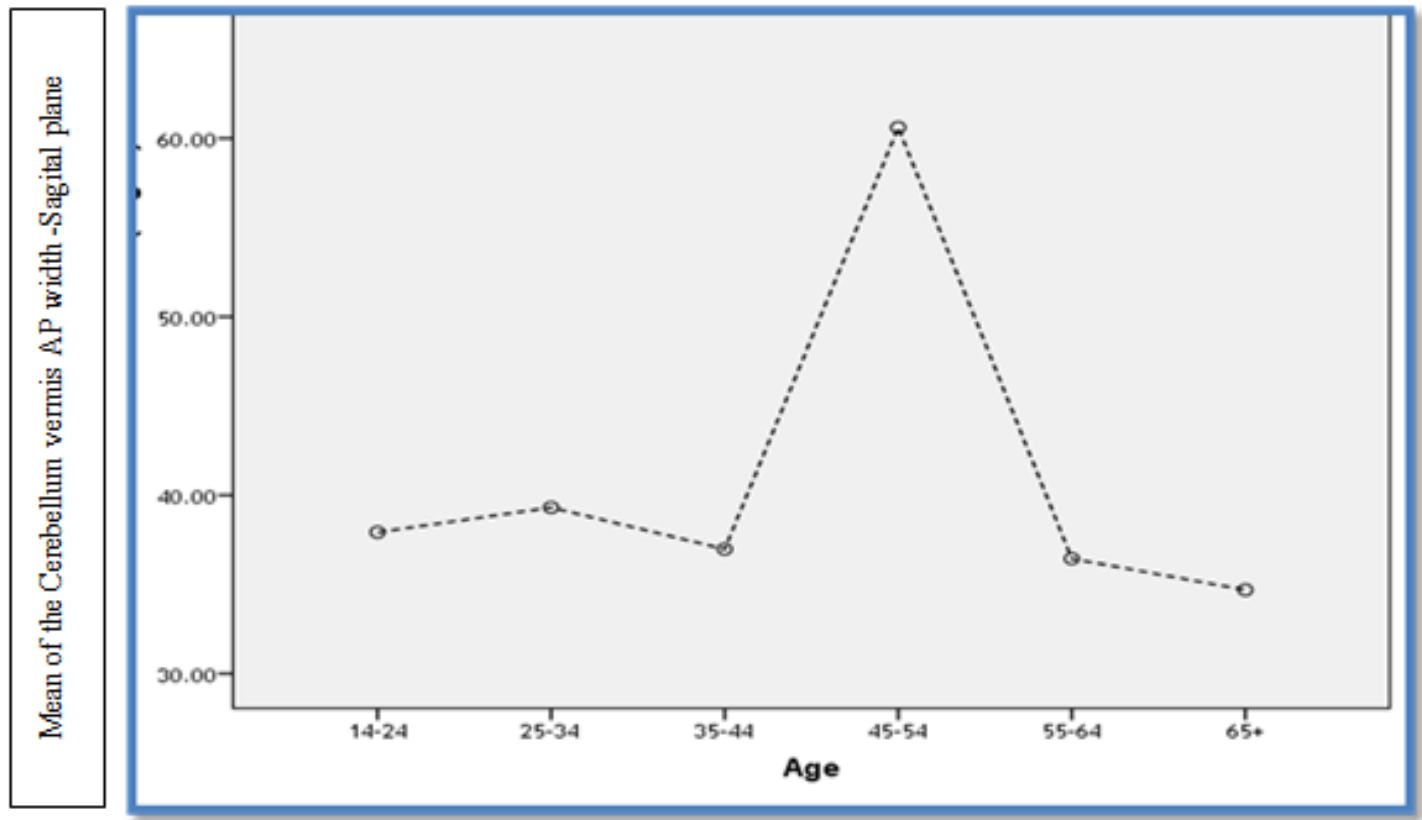

Figure 4: The mean plot of the measured cerebellum vermis AP width at saggital plane in different age groups

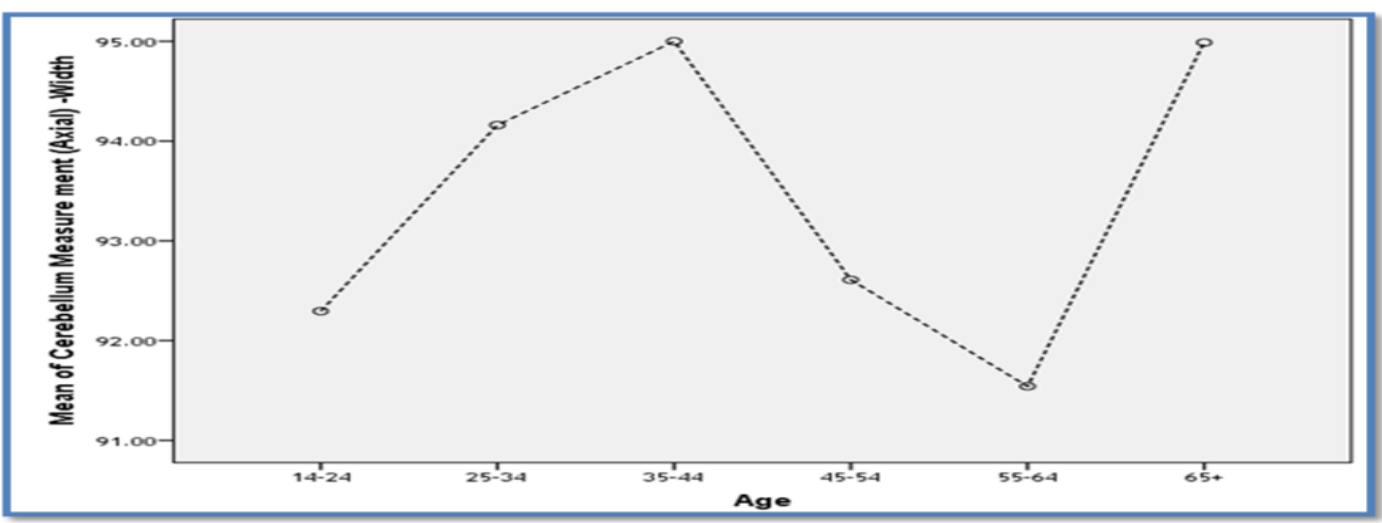

Figure 5: The mean plot of the measured cerebellum maximum width at axial plane in different age groups 


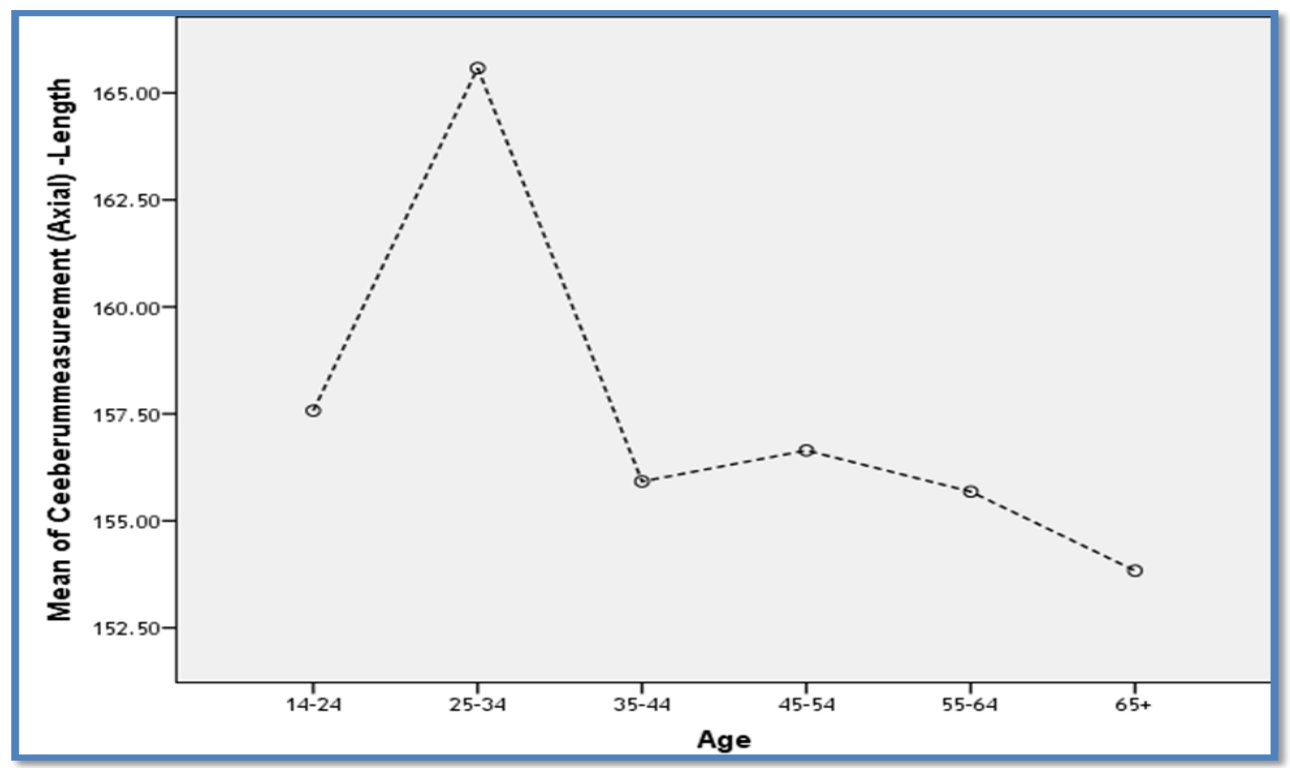

Figure 6: The mean plot of the measured cerebrum length at axial plane in different age groups

\section{DISCUSSION}

An awareness of normal neuroanatomic variability is important for understanding pathologic changes. In regard to the posterior fossa structures, the cumulative research record of in vivo studies is to some extents are few, and there is a need for normative data. In our prospective study, we examined two potential sources of normal variability in regional cerebellar and cerebrum measurements as seen in figures (1and2) including: age and gender. Table (1) shows the measurements of the cerebellum and cerebrum in axial and saggital planes. The results of this study provide a valuable addition to the normative database of the cerebellar and cerebrum anatomy for Sudanese. These data are an attempt to support the data for cerebellum norms measured in axial and saggital images. For presentation the concept of differential aging of the cerebellum: no significant age-related changes of the cerebellum were noticed, as seen in table (2) and figures (3,4and5)

Previous studies observed no age-related shrinkage of the cerebellum at the culmen noted, and there is mild decline in the area of lobules VIII through X of the cerebellum[18,14], this was similar to our findings that the cerebellum measurements were mildly declined at the ages between 45-54 years old , and 55-64 years by 3$4 \mathrm{~mm}$ in respectively for the maximum width of cerebellum hemisphere at the axial plane. An increasing in the measurements were detected after the age of 35-44years by $3 \mathrm{~mm}$ for the cerebellum height at maximum mid saggital plane, then it was reduced at the ages between 55-64 years, also by $3 \mathrm{~mm}$.The maximum value of cerebellum vermis AP width was found to be at the age between 45-54years old where an increasing by proportionally doubling in values was detected, with no significant impact of the aging and the cerebellum related measurements, this was presented in table (2).However this is a different approach from the observation in mostly archival samples. [14] Such inconsistency highlights the need for accumulation of a reasonably large sample of studies, in which each study's outcome is treated as a single observation. Only a review of multiple studies gives up significant estimation of the extent of age and gender differences in cerebellar anatomy. [19]

The present study results regarding the reduction or changing with age which were not significant; is in consistency to what was found in the previous study that mentioned that the mechanisms related to the observed patterns of discrepancy to aging is unclear, their study justified that the histologic findings of the aging cerebellum shows general atrophy, as the age-related loss of Purkinje cells is uniformly distributed across the vermian lobules and the cerebellar hemispheres [20]. Whatever the causes of changes of the cerebellar lobules VI and VII, they are not necessarily specific to aging, however a similar differential pattern has been observed in many diseases. [16, 21, 22, 23]

Another study has mentioned that the topography of the cerebellum blood supply may influence the cerebellum to differential aging. The cerebellar hemispheres are supplied by the branches of the posterior inferior cerebellar artery which originates in the vertebral artery, whereas the blood supply for the age-invariant superior vermis comes from the superior cerebellar artery, which branches off the basilar artery. [24,25]The vertebral system receives a small volume of blood in the age-related vertebral insufficiency [26], the cerebellar structures that are the most remote from the source may be at the greatest risk. This may be one of the causes of changes that observed in the cerebellum readings .On the other hand, one study mentioned that in contrast, the cerebellum shows no significant age related declines in blood flow, oxygen consumption, and glucose metabolism [16, 27, $28,29,30]$ 
Although this findings and changes are not significant but it is solely speculative, and of essential importance for more and further investigation with special attention to the evaluation of regional cerebrovascular variations within the cerebellum, as those patients may be at risk of cerebellum infarction.

Many studies have mentioned that the cerebellum undergo dramatic changes during childhood and adolescence. However, accurate characterization of occurring anatomical changes has been hindered by lack of longitudinal data and methodologic challenges in quantifying subdivisions of the cerebellum [7]

Cerebrum length at axial plane was found to be reduced significantly with aging at $\mathrm{p}=0.004$ as noticed in table (2).Several studies regarding brain, found aging associated with atrophy [31,32,33]. Others did not find age effects until ages $>55$ or $60[34,35,36]$. Our results support the hypothesis of neural atrophy associated with normal aging.

The design of the study optimized comparison of young to elderly subjects (ages from 14-80 years with mean age $42.36 \pm 17.87$ years. We evaluated the shape of the curve describing the relationship between brain changes and age, throughout the age range to determine whether the changes is linear or it was accelerating or declining at a certain age as noticed in figure (6)

This would require a larger sample in the fourth and fifth decade. However, it is noteworthy that Jernigan et al. [37] reported linear relationships with age for all measures. The additional findings concern gender differences is the comparison of length and width at axial planes. Studies have mentioned that women have lower brain volume, related to body and cranial size [33,34]. Our study showed smaller measurements of cerebellum and cerebrum in females than males, where the impact of gender was affected significantly for cerebellum hemisphere maximum width at axial plane at $p=0.040$ and cerebrum length at axial plane at $p=.005$ while the other measurements were not significantly correlated with gender, this was presented in table (3)

One study have mentioned that a differential effect of age on certain brain components were noticed, moreover there was a gender difference.[38]

The current study showed that there is no gender difference in cerebellum, height and AP vermian width, on the other hand; a significant difference in cerebellum maximum width between genders were observed table(3) reverse study have mentioned that there were no sex differences in the total vermian area with significant lobule 3 sex interaction, and indicated that men had differentially larger vermian lobules and revealed no sex differences in the areas of the posterior vermis and lobules VI and VII whereas the anterior vermian area was larger in men. The volume of the cerebellar hemispheres was also greater in men although the effect of sex was not equivalent across the hemispheres for the hemisphere The observed hemispheric volume differential between the genders was reliable. [39]

One comprehensive previous study [40] provided meaningful estimates of the magnitude of age and sex differences in cerebellar anatomy.

Our finding of larger cerebellar hemispheres in men is in agreement with the literature [12], for sex differences in brain morphology, the causes and mechanisms were found to be clarified. These differences are most likely of prenatal or perinatal origin, because in contrast to sex differences in body size, sexual dimorphism of cerebral and cerebellar size is observed in children before puberty [41] and cannot be attributed to post pubertal differences in sex hormones.

\section{CONCLUSIONS AND RECOMMENDATIONS}

Norms of Sudanese Cerebellum and Cerebrum were established. The normal aging concern the cereberum length, however no age related difference were noticed in the cerebellum measurements. The degree of the reduction in the cerebellar measurements is rather mild and unlikely to be significant

Smaller measurements of cerebellum and cerebrum were noticed in females than males, where the impact of gender was affected significantly in the cerebellum hemisphere maximum width and cerebrum length while the cerebellum height and AP vermian width were not significantly correlated with gender.

It should be taken into account in functional imaging studies of aging, when the cerebellum is considered as an appropriate structure for reference and normalization. These findings also raise a question of the relationship between age-related declines in multiple functions of the cerebellum and deterioration of their neuro-anatomic substrates.

Future investigation of sex differences in brain morphogenesis in utero with larger sample size as well at different ethnitity, this may shed light on gross neuroanatomic differences that are observed apparently throughout the normal life span.

\section{Acknowledgements}

We sincerely thank the participants without whom the study would not have been feasible. The Sudan University of Science and Technology, College of Medical Radiological Science and Yastabshroon Hospital Radiology Department -in which the study was obtained, are thankfully acknowledged. 


\section{REFERENCES}

[1]. Rapoport M, van Reekum R, Mayberg H. (2000)The role of the cerebellum in cognition and behavior: a selective review. J Neuropsychiatry Clin Neurosci;12:193-198

[2]. Gottwald B,Wilde B, Mihajlovic Z, et al.( 2004)Evidence for distinct cognitive deficits after focal cerebellar lesions. J Neurol Neurosurg Psychiatry; 75:1524-1531

[3]. Hopyan T, Laughlin S, Dennis M. (2010) Emotions and their cognitive control in children with cerebellar tumors. J Int Neuropsychol Soc;16:1027-1038

[4]. Ding H, Qin W, Jiang T, et al. (2012)Volumetric variation in subregions of the cerebellum correlates with working memory performance.Neurosci Lett;508:47-51

[5]. H. Selim Karabekir, M. Sirri Akosman, Nuket Gocmen-Mas, Funda Aksu,Mete Edizer, Omer F. Lenger, and Ismail Turkmenoglu, (2014)The Volume of Experimental Design Cerebellum:Stereological Microanatomic Study (J Craniofac Surg;25: 1492-1494)

[6]. Diamond, A., (2000). Close interrelation of motor development and cognitive development and of the cerebellum and prefrontal cortex. Child Dev. 71, 44-56.

[7]. Henning Tiemeier, Rhoshel K. Lenroot, Deanna K. Greenstein, Lan Tran, Ronald Pierson , Jay N. Giedd (2010) Cerebellum development during childhood and adolescence: A longitudinal morphometric MRI study NeuroImage 49 63-70

[8]. Kosar MI, Karacan K, Otag I, et al. (2012)Determination of cerebellar volume in children and adolescents with magnetic resonance images.Folia Morphol (Warsz);71:65-70

[9]. Susan S, Harold E, Jeremiah CH (2008) Gray's Anatomy, 40 ${ }^{\text {th }}$ edn. Spain: Churchill Livingstone, pp. 375-379, $297-309$.

[10]. Kemper TL. Neuroanatomical and neuropathological changes during aging and in dementia. In: Albert ML, Knoepfel EJE, eds. Clinical Neurology of Aging. 2nd ed. New York, NY: Oxford University Press; 1994:3-67

[11]. Raz N. (1996)Neuroanatomy of aging brain: evidence from structural MRI. In: Bigler ED, ed. Neuroimaging II: Clinical Applications. New York, NY: Academic Press;: 153-182

[12]. Raz N, Gunning FM, McQuain JM, et al. (1997)Selective aging of human cerebral cortex observed in vivo: differential vulnerability of the prefrontal gray matter. Cereb Cortex; 7:268-282

[13]. Schaefer GB, Thompson JN, Bodensteiner JB, Gingold M, Wilson M, Wilson D. (1991)Age-related changes in the relative growth of the posterior fossa. J Child Neurol;6:15-19

[14]. Raz N, Torres IJ, Spencer WD, White K, Acker JD. (1992)Age-related regional differences in cerebellar vermis observed in vivo. Arch Neurol;49:412-416

[15]. Shah SA, Doraiswami PM, Husain MM, et al. (1991)Assessment of posterior fossa structures with midsagittal MRI: the effects of age. Neurobiol Aging;12:371-374

[16]. Naftali Raz, James H. Dupuis, Susan D. Briggs, Catherine McGavran, and James D. Acker (1998).Differential Effects of Age and Sex on the Cerebellar Hemispheres and the Vermis:A Prospective MR Study AJNR Am J Neuroradiol 19:65-71

[17]. Ramnani, N., (2006). The primate cortico-cerebellar system: anatomy and function. Nat. Rev. Neurosci. 7, $511-522$.

[18]. Schaefer GB, Thompson JN, Bodensteiner JB, Gingold M, Wilson M, Wilson D. (1991)Age-related changes in the relative growth of the posterior fossa. $J$ Child Neurol;6:15-19

[19]. Hedges L, Olkin I. Statistical Methods for Meta-Analysis. Orlando, Fla: Academic Press; 1985

[20]. Ellis RS. (1920)Norms for some structural changes in human cerebellum from birth to old age. J Comp Neurol;32:1-33

[21]. Courchesne E. (1987)A neurophysiological view of autism. In: Schopler E, Mesibov G, eds. Neurobiological Issues in Autism. New York, NY:Plenum;:285-384

[22]. Raz N, Torres IJ, Briggs SD, et al. (1995)Selective neuroanatomical abnormalities in Down's syndrome and their cognitive correlates:evidence from MRI morphometry. Neurology;45:356-366

[23]. Cieselski KT, Yanofsky R, Ludwig RN, et al. (1994)Hypoplasia of the cerebellar vermis and cognitive deficits in survivors of childhood leukemia. Arch Neurol;51:985-993

[24]. Lister JR, Rhoton AL Jr, Matsushima T, Peace DA. (1982)Microsurgical anatomy of the posterior inferior cerebellar artery. Neurosurgery;10:170-199

[25]. Hardy DG, Peace DA, Rhoton AL Jr. (1980) Microsurgical anatomy of the superior cerebellar artery. Neurosurgery;6:10-28

[26]. Baloh RW. (1984)Neurotology of aging: vestibular system. In: Albert ML, ed. Clinical Neurology of Aging. New York, NY: Oxford University Press;:345-361

[27]. Kushner M, Tobin M, Alavi A, et al. (1987)Cerebellar glucose consumption in normal and pathologic states using fluorine-FDG and PET.J Nucl Med;28:1667-1670

[28]. Marchal G, Rioux P, Petit-Taboue' MC, et al. (1992)Regional cerebral oxygen consumption, blood flow, and blood volume in healthy human aging. Arch Neurol;49:1013-1020

[29]. Loessner A, Alavi A, Lewandrowski KU, Mozley D, Souder E, Gur RE. (1995)Regional cerebral function determined by FDG-PET in healthy volunteers: normal patterns and changes with age. J Nucl Med;36:1141-1149

[30]. Moeller JR, Ishikawa T, Dhawan V, et al. (1996)The metabolic topography of normal aging. J Cereb Blood Flow Metab;16:385398

[31]. Pearl, T. (1905) Biometrika 4, 13-1045

[32]. Peress, N. S., Kane, W. C. \& Aronson, S. M. (1973) in Progressive Brain Research, ed. Ford, D. H. (Elsevier, Amsterdam), Vol.40.

[33]. Pakkenberg, H. \& Voight, J. (1964) Brain weight of the Danes. a forensic material acta Anat. 56, $297-307$.

[34]. Marshall, J. (1892) J. Relations between the Weight of the Brain and its Parts, and the Stature and Mass of the Body, in Man.Anat. Physiol. 26, 445-500.

[35]. Marchand, F. (1902) gender difference in age effect on brain atrophy measured by magnetic resonance imaging .Biol. Zentralbl. 22, 376-382.

[36]. Miller, A. K. H., Alston, R. L. \& Corsellis, J. A. N. (1980) variation with age in the volume of grey and white matter in the cerebral hemispheres of man : measurements with an image analysers neuropathology.appl. neurobiol. 6, 119-132.

[37]. Jernigan T. L., Press, G. A. \& Hesselink, J. R. (1990)Clinical Neurology of aging. Arch. Neurol.(Chicago) 47, $27-32$.

[38]. Botwinick, J. (1967) Cognitive Processes in Maturity and Old Age (Springer, New York).

[39]. Ruben C. Gurt, P. David Mozley, Susan M. Resnick, Gary L. Gottlieb, Mark Kohni,Robert Zimmermant, Gabor Hermant, Scott Atlast, Robert Gross manf, Deborah Berretta, Roland Erwin, And Raquel E. Gur (1991) .Gender Differences In Age Effect On Brain Atrophy Measured By Magnetic Resonance Imaging Proc. Natl. Acad. Sci. Usavol. 88, Pp. 2845-2849.

[40]. Hedges L, Olkin I. Statistical Methods for Meta-Analysis. Orlando,Fla: Academic Press; 1985

[41]. Giedd JN, Snell JW, Lange N, et al. (1996)Quantitative magnetic resonance imaging of human brain development: ages 4-18. CerebCortex;6:551-560 